\title{
Role of the pharmacist in reducing healthcare costs: current insights
}

This article was published in the following Dove Press journal:

Integrated Pharmacy Research and Practice

25 January 2017

Number of times this article has been viewed

\section{Kieran Dalton \\ Stephen Byrne}

Pharmaceutical Care Research Group, School of Pharmacy, University

College Cork, Cork, Ireland
Correspondence: Kieran Dalton Pharmaceutical Care Research Group, School of Pharmacy, University College Cork, College Road, Cork, Ireland

$\mathrm{Tel}+353$ 2I 490 I690

$\mathrm{Fax}+353214901656$

Email kieran.dalton@ucc.ie

\begin{abstract}
Global healthcare expenditure is escalating at an unsustainable rate. Money spent on medicines and managing medication-related problems continues to grow. The high prevalence of medication errors and inappropriate prescribing is a major issue within healthcare systems, and can often contribute to adverse drug events, many of which are preventable. As a result, there is a huge opportunity for pharmacists to have a significant impact on reducing healthcare costs, as they have the expertise to detect, resolve, and prevent medication errors and medication-related problems. The development of clinical pharmacy practice in recent decades has resulted in an increased number of pharmacists working in clinically advanced roles worldwide. Pharmacistprovided services and clinical interventions have been shown to reduce the risk of potential adverse drug events and improve patient outcomes, and the majority of published studies show that these pharmacist activities are cost-effective or have a good cost:benefit ratio. This review demonstrates that pharmacists can contribute to substantial healthcare savings across a variety of settings. However, there is a paucity of evidence in the literature highlighting the specific aspects of pharmacists' work which are the most effective and cost-effective. Future high-quality economic evaluations with robust methodologies and study design are required to investigate what pharmacist services have significant clinical benefits to patients and substantiate the greatest cost savings for healthcare budgets.
\end{abstract}

Keywords: pharmacoeconomics, pharmaceutical care, clinical pharmacy, cost-effectiveness, economic evaluation

\section{Introduction}

The role of the pharmacist has evolved substantially in recent decades. The traditional activities of the profession primarily focused on the dispensing and supply of medications, while interaction with other healthcare professionals was somewhat limited. Nowadays, pharmacists also ensure the rational and cost-effective use of medicines, promote healthy living, and improve clinical outcomes by actively engaging in direct patient care and collaborating with many healthcare disciplines. With this expanding scope of practice, pharmacists are being recognized as key components in providing individualized patient care as part of interprofessional healthcare teams.

\section{Escalating healthcare costs}

Healthcare costs are rising worldwide, due to the combination of an aging population, technological advances, the prevalence of medication errors, and increased spending on medicines year on year. ${ }^{1}$ As the global population ages, healthcare organizations are 
challenged with the increasing burden of chronic diseases and polypharmacy among older adults. ${ }^{2}$ The increased number of medicines being consumed by the elderly, as well as the rising cost of newer pharmacotherapies, has intensified the pressure on healthcare organizations to identify and implement cost-control measures. Pharmacists have a major role in lowering costs by critically reviewing the pharmacotherapy of multimorbid elderly patients. The reduction of inappropriately prescribed medicines not only produces savings in the cost of each individual medicine but also reduces the risk of adverse drug events (ADEs) that often contribute to prolonged and expensive hospital admissions.

Under constrained financial conditions, healthcare services need to demonstrate that they remain cost-effective, given the investment in their provision. ${ }^{3}$ Numerous publications describe the diversifying role of pharmacists in a variety of practice settings, ${ }^{4,5}$ and these are not just limited to developed countries. ${ }^{6}$ Previous review articles have shown positive economic outcomes associated with pharmacist interventions and clinical pharmacy services. However, despite these developments, this has not diminished the need to prove continually the economic benefit of such services, as some of the papers included in these review articles did not include full economic evaluations. ${ }^{5,7-10}$

\section{Pharmacoeconomics, cost savings, and cost avoidance}

The continuing high cost of medicines emphasizes the increasing importance of pharmacoeconomic evaluation studies. ${ }^{11}$ These studies allow us to identify, measure, and compare the cost of different pharmacotherapies or services and what significance they will have on healthcare budgets and patient health. In this field, pharmacists can have a major influence on healthcare decision makers with regard to better allocation of resources and expenditure, so as to optimize population health from the use of medicines. ${ }^{12}$ With their unique knowledge of medicines, pharmacists are central figures in decreasing healthcare expenditure through cost savings on medicines and cost avoidance. Cost savings allude to reductions in current spending due to changes in the expense on a patient's treatment, eg, switching from intravenous to oral therapy where appropriate. In contrast, cost avoidance refers to an intervention that reduces potential future spending that may have occurred without the intervention. An example of this would be a pharmacist suggesting the discontinuation of a potentially inappropriate medicine in an elderly patient which could result in a future ADE, hence reducing the potential cost of a general practitioner (GP) referral or hospital admis- sion, as well as eliminating the actual cost of the medicine. ${ }^{3}$ Over an extended period of time, limiting costs through cost avoidance measures can result in significant cost savings.

\section{Medication errors, inappropriate prescribing, and ADEs}

Medication errors and inappropriate prescribing are recognized as major problems, both clinically and economically, for the healthcare system. They can contribute to adverse drug reactions (ADRs) and ADEs, especially in elderly patients, and can have a major impact on patient morbidity and mortality. ${ }^{13}$ ADEs can result in increased healthcare utilization, as well as extend hospital admissions, hence incurring further medical costs. ${ }^{14}$ One large study demonstrated that ADRs were responsible for $6.5 \%$ of hospital admissions, ${ }^{15}$ while a recent meta-analysis showed that ADEs may occur in $16.88 \%$ of patients during hospitalization. ${ }^{16}$ Patients affected by an ADE have their hospital admission prolonged by an average of 2 days, at an additional expense of $\sim$ US $\$ 2,000-\$ 2,500 .{ }^{17}$ Medication errors are very costly to healthcare systems, but a large portion of these are preventable. ${ }^{18-20}$ Pharmacists have demonstrated a positive effect in preventing medication errors and limiting inappropriate prescribing, thus reducing healthcare costs by preventing hospital admission or reducing hospital length of stay (LOS). ${ }^{21}$

\section{Aim}

The aim of this paper was to provide a comprehensive narrative overview of the role of pharmacists in reducing costs in a variety of different healthcare settings.

\section{Materials and methods}

A comprehensive electronic literature search was conducted using the following databases from inception up to and including November 2016: PubMed, Medline (Ovid), CINAHL, Science Direct, and Google Scholar. Key search terms included but were not limited to: "pharmacist" AND "cost" AND "economic evaluation" AND "hospital" AND "community pharmacy", as well as various synonyms or combinations of these terms. Other search methods included citation searching and scanning reference lists of highly cited key papers.

\section{Community pharmacists}

The long-established image of community pharmacists has been based on a transactional model, primarily focused on the preparation, dispensing, and supply of medicines. However, this profession has transformed considerably in recent times, and faces further radical changes as it moves toward 
providing services and playing a greater role in health promotion and disease prevention. Community pharmacists are one of the most accessible healthcare providers and hence are in a unique position to provide a patient-focused primary healthcare service to their community.

Most primary care physicians do not have enough time to provide all of the preventive and chronic disease services that patients require, and this is where other members of the multidisciplinary team can make a valuable contribution in picking up any shortfalls. ${ }^{22}$ Pharmacists can play a vital role in filling many of these gaps, as they have more time and the appropriate expertise to provide high-quality patient-centered health care. ${ }^{10}$

\section{Chronic disease management}

Chronic diseases are the leading cause of death and disability worldwide, and their management accounts for more than twothirds of global healthcare expenditure. ${ }^{23,24}$ Pharmacists have the potential to play a greater role in the management of chronic illnesses and make considerable savings in healthcare costs. As frontline healthcare professionals, community pharmacists are in contact with this patient cohort regularly, are specially trained to reduce disease severity, monitor medication therapy to achieve desired clinical effects, reduce adverse health events, and can make recommendations to patients or prescribers regarding pharmacotherapy where appropriate. Studies have shown that pharmacists in primary care have the skills to manage patients with long-term conditions, and this can result in both clinical and cost benefits for a variety of chronic illnesses, such as cardiovascular disease, chronic obstructive pulmonary disease, and diabetes. ${ }^{25-27}$ The expanded role of pharmacists managing chronic diseases is commensurate with the extensive training and knowledge associated with the profession. ${ }^{28}$

Community pharmacists are ideally placed to undertake health screenings for disease prevention and progression, and to aid in the diagnosis of new diseases (eg, type 2 diabetes). Pharmacy-based health checks have been shown to be cost-effective when actively screening at-risk patients..$^{29}$ The delivery of point-of-care testing in community pharmacies may be used not only for screening purposes but also in the management of chronic diseases. Although these services may incur initial costs, such as training and purchase of equipment, their provision in this setting can reduce patient attendance at time-constrained GP offices, as well as allow patients to conveniently check clinical parameters such as cholesterol, blood glucose, and $\mathrm{HbA}_{1 \mathrm{c}}$, and receive their results in a timely manner. Community pharmacists can utilize this information to monitor the patients' control of their chronic disease and improve clinical outcomes. ${ }^{30}$
In the management of hypertension, pharmacists have been shown to improve patient outcomes and represent a cost-effective alternative in comparison to those managed by physicians. ${ }^{31}$ Community pharmacy-managed anticoagulation services have been shown to improve chronic anticoagulation control with decreased bleeding and thromboembolic events. ${ }^{32}$ When compared with usual medical care, one study found that pharmacist-run services made savings of $\$ 647,024$ by preventing hospital admissions and emergency department (ED) visits. ${ }^{33}$ The clinical and economic benefits of community pharmacist involvement in chronic disease management have been well defined. It is envisioned that community pharmacists can take on greater roles in chronic disease management and help generate significant healthcare cost savings in the future.

\section{Adherence}

Medication adherence may be defined as "the extent to which patients take medications as prescribed by their healthcare providers" ${ }^{34}$ Even though good medication adherence correlates with positive health outcomes, ${ }^{35}$ it is estimated that between $20 \%$ and $50 \%$ of patients in developed countries may be nonadherent with their medications. ${ }^{36,37}$ Nonadherence is associated with potential disease progression, pharmacotherapeutic failure, and hospitalization. ${ }^{38} \mathrm{~A}$ study from the US found that $33 \%-69 \%$ of medication-related hospital admissions may be due to poor medication adherence. ${ }^{34}$

Medication nonadherence is an economic burden worldwide, and it is estimated that the annual cost of nonadherence is $\$ 100$ billion in the US alone. ${ }^{39}$ Although improvements in adherence lead to increased spending on medicines, this results in an overall reduction in medical costs. ${ }^{40}$ Therefore, an intensive effort is required to improve patients' adherence to their pharmacotherapy. Community pharmacists can have a major impact on patient adherence, as they are uniquely positioned to identify patients who may not be taking their medicines as prescribed, the reasons for this, and can intervene at the point of medication supply by providing education and counseling where appropriate. Studies have shown that pharmacists can improve medication adherence rates, resulting in improved patient outcomes. ${ }^{41,42}$ However, more research must be done to evaluate the true economic benefits of such interventions.

\section{Medicines use review}

It is important to highlight that patients' use of medicines should be reviewed for appropriateness before adherence is encouraged. This is particularly the case with elderly patients, who may be on multiple medicines, where adherence may 
have adverse consequences. A medicines use review (MUR) involves a private discussion between a pharmacist and a patient, whereby the goal is to improve the patient's knowledge, adherence, and use of medicines. ${ }^{43}$ MURs also provide an opportunity for a pharmacist to review a patient's pharmacotherapy, including both prescribed and over-the-counter (OTC) medicines. Pharmacists can identify which medicines a patient may not be taking, as well as potentially inappropriate medicines, helping to reduce wastage and optimize care. It was estimated in 2009 that the gross annual cost of the National Health Service (NHS) primary care and community care prescription medicine wastage was $£ 300$ million per year in England, including $£ 90$ million worth of unused prescription medicines that are retained in individuals' homes and $£ 110$ million returned to community pharmacies. ${ }^{44}$ With an aging multimorbid population worldwide, polypharmacy will continue to be a serious issue, and hence MURs by community pharmacists will be significant in order to curb healthcare costs. Even though robust research evidence is lacking with regard to the clinical and cost-effectiveness of MURs, a recent article found that their value is now largely accepted, and that the benefit of these MURs outweighs any costs that they may incur. ${ }^{45}$

\section{Selection of OTC items}

The number of medicines available without a prescription is growing rapidly; there are currently over 300,000 OTC medicinal products available in the US market alone. ${ }^{46}$ Pharmacists play an important role in safeguarding their patients, especially the elderly, from potentially inappropriate use of OTC medicines. Pharmacists often provide advice or nonpharmacological approaches as first-line solutions, hence saving on the cost of purchasing an OTC item unnecessarily. ${ }^{47}$ If an OTC product is required, pharmacists help their patients choose a safe and appropriate option tailored to their individual needs. Pharmacists recommend using generic medicines rather than high-cost branded alternatives, reducing the cost to the patient and healthcare system. Selfmedication with OTC products has been shown to contribute to ADRs and hospital admissions. ${ }^{48}$ With the advice and recommendations of a community pharmacist, patients can avoid spending money on ineffective or potentially harmful OTC medications; this helps limit further healthcare utilization by patients, such as GP or ED visits.

\section{Management of minor ailments}

According to a recent report in the UK, $5 \%$ and $13 \%$ of presentations to EDs and GPs, respectively, represent minor ailments that could be managed in community pharmacies. ${ }^{49}$ In this way, community pharmacists can play an important role in reducing the clinical and economic burden of minor ailment consultations on other higher cost areas of the health service. Pharmacists are specially trained in managing these self-limiting conditions and deal with them daily as part of their normal practice, such as colds and flu, hay fever, and various aches and pains. ${ }^{50} \mathrm{Pharmacists}$ can provide first aid to patients free of charge in the management of minor injuries to help avoid or reduce potentially costly trips to the ED. Community pharmacists are available at convenient hours and usually require no appointment, helping to keep minor ailments out of the GP setting but also ensuring that patients with potentially serious illnesses are filtered through to their GP. ${ }^{51}$

State-funded minor ailment schemes are available across the UK and Canada, ${ }^{52}$ whereby pharmacists provide consultations to patients for a wide variety of minor ailments. Patients who are exempt from prescription charges receive the medicines free of charge, whereas patients who routinely pay for their medicines must pay the pharmacy a standard prescription charge. The government reimburses the pharmacy for the cost of the medicine and provides remuneration for the pharmacist's time. These repayments should allow for further development of pharmacy services. Other countries, such as New Zealand, are currently evaluating the feasibility of introducing similar minor ailment schemes, while a pilot study is being undertaken in Ireland. ${ }^{53,54} \mathrm{~A}$ UK report suggested that GPs treating minor ailments is costing the NHS $£ 2$ billion per year. ${ }^{55}$ Community pharmacy minor ailment schemes can save physician time spent with minor illnesses and enables them to focus on patients with more complex medical issues. This may contribute to shorter waiting times, unclogged GP surgeries, and enhanced patient access to services. ${ }^{56}$

The cost benefits of minor ailment schemes are clear. Patients consulting more costly branches of the healthcare system for minor ailments that could have been dealt with in a community pharmacy is a waste of resources, patients' time, and GPs' time. ${ }^{50}$ Studies have shown that community pharmacists' management of minor ailments, as well as the patients' health-related outcomes, is equivalent to those seen in higher cost settings. ${ }^{49}$ Additional economic evaluations will be required to highlight the continuing cost benefits that these schemes can achieve.

\section{Other services available in community pharmacies}

The delivery of additional services through community pharmacies presents considerable cost savings to both the public 
and government-funded healthcare systems. Expanding the number of medicines and services that community pharmacists can provide can reduce patients' requirements to seek more expensive areas of the healthcare sector. For example, timely access to emergency hormonal contraception without prescription has been a welcome addition to community pharmacies worldwide, avoiding any extra expense or time delay in consulting with a physician. ${ }^{57}$

Pharmacy-provided vaccination services have expanded the scope of practice for pharmacists, and they resemble a lower cost substitute when compared to those that are physician-administered. ${ }^{58}$ It has been shown that immunization rates against influenza are significantly higher for individuals aged $>65$ years in areas where pharmacists provide vaccinations, ${ }^{59}$ most likely due to improved accessibility and convenient locations for patients to be vaccinated in pharmacies. ${ }^{60}$ Increased vaccination rates have been shown to reduce deaths and hospitalizations in elderly patients, and thus increased vaccination rates should translate into more cost savings due to reductions in direct medical care. ${ }^{61}$

\section{Hospital pharmacists}

Hospital pharmacists have had a major influence on the advancement of pharmacy practice in recent decades. ${ }^{62}$ In many countries, hospital pharmacists have expanded their roles beyond the dispensary, and now routinely provide clinical pharmacy services at ward level, which includes reviewing patients' medications and advising other healthcare professionals with regard to pharmacotherapy. ${ }^{63}$ However, in several regions worldwide, the evolution of hospitalpharmacy practice is not happening quickly enough. In these areas, particularly in some parts of Africa and Asia, hospital pharmacists have been predominantly limited to dispensarybased roles, meaning that their expertise in medicine management is being underutilized. ${ }^{62,64}$

Hospital pharmacists represent a key component of the multidisciplinary team involved directly in patient-centered care. When delivered as a core clinical service, pharmacistmanaged medication therapy has been associated with reduced medication errors, ADRs, mortality, and LOS. ${ }^{65}$ In many developed countries, hospital pharmacists are working at advanced levels clinically in a wide array of specialized roles, ${ }^{63}$ with an increased number of independent and/or supplementary pharmacist prescribers. ${ }^{66}$ Specialization allows pharmacists to deliver enhanced care to patients or to a selected group of patients, and hence may prove to be beneficial in reducing expenditure for healthcare providers. ${ }^{67}$
In order to justify the provision of additional pharmacy services, it is no longer adequate to substantiate the clinical benefits of the service alone. Cost-effectiveness data is a necessity. ${ }^{68}$ Several review articles have demonstrated the overall cost-effectiveness of hospital pharmacists' activities in a wide variety of clinical specialties, such as ED and intensive care unit (ICU) pharmacists, pharmacists managing therapeutic drug monitoring of antibiotics and antiepileptics, and those who specialize in the optimization of antimicrobial therapy., ${ }^{4,10,68-70}$ However, some of the economic evaluations only contained partial cost analyses; therefore, this may limit the strength of the conclusions provided. ${ }^{8,10}$

Hospital pharmacists' clinical activities often include medicines reconciliation at transition points of care, medication management reviews for inpatients, provision of medicines information to other healthcare professionals, selection of drug therapy, monitoring patients for an appropriate therapeutic response to medicines, identifying and reporting ADRs, patient counseling, as well as other duties to ensure the safe and effective use of medicines in this setting. ${ }^{71}$ Pharmacist interventions are a key component to a hospital pharmacist's role in preventing medication-related problems (MRPs) and have been defined as "any action by a clinical pharmacist that directly results in a change in patient management or therapy", ${ }^{72}$ Evidence from the literature is quite mixed with regard to the cost-effectiveness of pharmacists' interventions and related measures, such as health outcomes and quality of life. ${ }^{73}$ However, many studies have proven that pharmacist interventions have a positive impact on hospital budgets, but it is difficult to elucidate which interventions were the most cost-effective. ${ }^{74,75}$ Cost-saving interventions often include discontinuing unnecessary medicines, switching to less expensive agents, or altering the route of administration. ${ }^{76}$ However, previous research has suggested that cost avoidance measures, such as preventing ADEs and further healthcare utilization, have the greatest cost:benefit ratio. ${ }^{68}$ Cost avoidance calculations in this setting are usually based on ADE probability in the absence of pharmacist intervention. ${ }^{9}$ ADEs can cause hospitalization or prolong LOS and may even result in serious harm or death. Reducing LOS is the key to cost savings. Therefore, by preventing ADEs and shortening LOS over a period of time, pharmacists can make substantial cost savings in healthcare budgets. ${ }^{3}$ In this way, hospital pharmacists act as risk managers by eliminating additional costs due to ADEs which would have been incurred in the absence of any intervention. ${ }^{77}$ 


\section{Medicines reconciliation and transitions of care}

Although it is one of the more challenging aspects of inpatient care, medicines reconciliation has been proven to reduce medication errors and subsequent harm to patients at transition points of care. ${ }^{21,78}$ An accurate medication list at hospital admission in particular is vital when evaluating patients' current pharmacotherapy and in determining further treatment options. ${ }^{79}$ Studies have established that best possible medication histories attained by pharmacists are more precise and more comprehensive than those obtained by other healthcare practitioners. ${ }^{80}$ Furthermore, pharmacist-led reconciliation has been shown to have the highest expected cost benefits when compared with other reconciliation processes. ${ }^{81}$

However, a recent systematic review revealed that undertaking medicines reconciliation alone at discharge is insufficient in reducing postdischarge clinical outcomes, and that the approach should be multifaceted, incorporating a clinical medication review during admission and patient counseling. Consequently, hospital pharmacists are being given the opportunity to take up more proactive roles in the management of patients' care transitions, where there is an increased risk of medication error. ${ }^{82} \mathrm{~A}$ cost-effectiveness evaluation indicated that discharge counseling by pharmacists was cost saving in $48 \%$ of scenarios, but all scenarios were cost-effective at a low willingness-to-pay value. High-risk elderly patients appeared to benefit most from this service. ${ }^{83}$ It has been shown that pharmacists' involvement at admission and discharge has resulted in reduced medication errors and ADEs, as well as a substantial decrease in the rate of all-cause ED visits and hospital readmissions. ${ }^{21,78}$ Although these outcomes should produce significant cost savings for healthcare providers, further studies must be conducted to quantify the exact economic benefits of these results as pharmacists continue to lead the way in delivering effective transitional care.

\section{Inpatient medication review}

Hospital admission appears to be an opportune time at which a pharmacist can comprehensively review a patient's pharmacotherapy; this is especially of value where the hospitalization may have been drug-related or in patients with complex medication regimens, such as the multimorbid elderly receiving polypharmacy. Medication reviews allow hospital pharmacists to identify any MRPs and formulate their recommendations to resolve these issues with their fellow healthcare professionals. MRPs can be very costly to healthcare providers, as they can result in hospitalization, as well as increased LOS and cost of stay ${ }^{84}$
In contrast to the primary care setting, a hospital pharmacist can perform a more thorough medication review with access to all patient data and assess the pharmacotherapy in the context of the patient's presenting conditions and symptoms. They are often carried out in conjunction with medicines reconciliation on admission. Moreover, the pharmacist can interview the patient and have a face-to-face discussion with the prescriber regarding any unresolved MRPs. Although there are very few robust health economic analyses focusing on medication reviews by hospital pharmacists, a review of the literature found no studies where the intervention cost outweighed the benefit. Despite the shortage of definitive research regarding cost- and clinical effectiveness, the value of hospital pharmacist medication reviews is now commonly accepted in comparison to standard care. Nonetheless, additional research substantiating this belief would be beneficial.

\section{Ward rounds}

Traditionally, hospital pharmacists have provided their clinical services to wards by carrying out daily ward visits, where they address any MRPs identified with appropriate interventions. The pharmacist's role in prescribing is usually retrospective, where there may be long delays between the time of prescription and the pharmacist's intervention, increasing the risk for costly ADEs. Therefore, it may be more advantageous for a pharmacist to be present at the time of prescribing, providing their specialized knowledge when it may be needed most. ${ }^{85}$

It has been shown that pharmacist participation in consultant-led ward rounds in addition to the ward-pharmacist visit allows for significantly more interventions to be achieved per patient in comparison to the ward-pharmacist visit alone ${ }^{86}$ Although attending daily ward rounds may be timeconsuming for pharmacists, it is an excellent opportunity to prevent ADEs and significantly reduce healthcare costs. ${ }^{85-87}$ Similarly, the presence of a pharmacist on a post-admission ward round allows for early amendment of discrepancies from the medication history and can result in reduced risk for patients and lower prescribing costs. ${ }^{88}$

\section{Specialized roles}

The literature is replete with publications that describe the pivotal role that pharmacist interventions can play in improving healthcare outcomes and decreasing costs in a variety of practice settings. ${ }^{9,7489} \mathrm{In}$ an ICU setting, pharmacists are valued practitioners, as they can provide advice to physicians regarding complex pharmaceutical regimens in critically ill patients, often involving high-cost medicines. Pharmacists 
have a positive impact in this high-risk environment by preventing ADEs, reducing morbidity and mortality, and limiting overall healthcare costs. ${ }^{70}$ A recent Dutch paper demonstrated that a pharmacist in an ICU setting can have a significant impact on reducing prescribing errors and preventable ADEs, bringing about cost savings even with limited time investment. The ICU physicians in this study were not accustomed to ward-based pharmacist recommendations, and yet the high acceptance rate of $74 \%$ emphasizes how clinically pertinent these interventions were..$^{90}$

In the ED setting, pharmacists' activities include the provision of medicines information, medication chart review, toxicology consultation, and eliminating medication errors at the earliest point of admission. A medication history ascertained by an ED pharmacist with subsequent medicines reconciliation increases the likelihood of obtaining an accurate medication chart for a patient early in their hospital stay. ${ }^{91}$ Pharmacist interventions have been linked with significant cost-avoidance figures in this high-risk environment. ${ }^{69}$ One study from the US demonstrated that the implementation of a 24-hour ED pharmacy service allowed for pharmacist interventions to prevent serious patient harm and would extrapolate to an annual cost saving of $\$ 1,691,185 .^{92}$

Against a backdrop of increasing antimicrobial resistance, pharmacists are major drivers in promoting antimicrobial stewardship worldwide. ${ }^{93}$ Many hospitals now have pharmacists who specialize in this area of stewardship, ensuring the rational use of antimicrobials with improved patient outcomes, and are often involved in the development of the hospital's antimicrobial guidelines. Streamlining antimicrobial therapy is a key responsibility of this specialized role, whereby cost savings are generated from discontinuing the inappropriate use of certain agents, and promoting the conversion from parenteral to oral administration without negatively affecting patient care. These savings are primarily made through reduced antimicrobial costs and reduction in LOS. ${ }^{94}$ One study showed that pharmacist involvement in surgical antibiotic prophylaxis contributed to a $52.1 \%$ lower mortality rate, a $10.2 \%$ reduction in LOS, and a $34.3 \%$ lower incidence of postoperative infections compared with hospitals without pharmacist involvement in surgical antibiotic prophylaxis..$^{95}$

\section{Chemotherapy services}

The rise in cancer incidence worldwide has resulted in an increased number of prescriptions for antineoplastic agents. Chemotherapy regimens may be highly complex and are more susceptible to error, as they necessitate frequent dosage adjustments. Medication errors involving these regimens may be catastrophic due to the drugs' narrow therapeutic index, and thus pharmacist involvement is crucial. ${ }^{96}$ One study showed that even though the overall pharmacist intervention rate was low $(1.59 \%)$, just over $50 \%$ of these interventions were considered to be higher than clinically "significant", including 11\% of cases being "very significant" or "extremely significant", producing an annual net cost benefit of $\$ 116,493 .{ }^{97}$ This highlights that the presence of a pharmacist in a chemotherapy preparation unit can prevent ADEs in a high-risk environment and result in a noteworthy positive effect on hospital budgets.

\section{Pharmacists in other clinical settings Long-term care}

Residents in long-term care are often elderly people with several comorbid conditions, who may be very susceptible to inappropriate prescribing. Although complex medication regimens are often required for these individuals, pharmacists can play a vital role in improving the overall quality of drug therapy. ${ }^{98}$ The pharmacist's medication review saves doctors' time; this is particularly the case for patients who are not reviewed opportunistically. Overall, the evidence for the benefit of pharmacists in long-term care settings is quite mixed. Pharmacists can improve clinical outcomes by reducing potentially inappropriate prescribing and MRPs; however, the majority of successful interventions in the literature were multidisciplinary in nature. One study involved pharmacists performing medication reviews, followed by discussion of MRPs with medical and nursing staff: $94 \%$ of the pharmacist's recommendations were accepted, and the success was attributed to effective multidisciplinary communication. ${ }^{99}$ Economic evaluations of pharmacist interventions in this setting are limited, but most studies have shown no significant difference in humanistic and economic outcomes. ${ }^{73}$

\section{Ambulatory care clinics}

Pharmacist-managed ambulatory care clinics are becoming increasingly more prevalent in North America. Most of these clinics are located in primary care medical centers, where pharmacists perform patient assessments, provide collaborative drug therapy management, and can order medication therapyrelated tests. The delegation of some medication management responsibilities, such as prescribing, to an ambulatory care pharmacist frees up time for GPs and reduces patient waiting lists, resulting in increased patient satisfaction scores. ${ }^{100}$

However, the integration of these clinics into primary care has encountered various barriers, such as the lack of 
reimbursement for pharmacy services. A common implementation model for these services includes a disease-specific chronic care management model, whereby a pharmacist will focus on the management of one chronic disease in particular (eg, chronic obstructive pulmonary disease, type 2 diabetes). Studies from the US have demonstrated that pharmacists in this setting had a positive effect on both clinical and cost outcomes, whereby patients achieved their therapeutic goals, resulting in reduced hospital readmission rates. ${ }^{100,101}$ Legislation changes may be required in some jurisdictions to allow for reimbursement of pharmacist services and further expansion of the pharmacist role in primary care, providing a valued service to underserved populations.

\section{Conclusion}

Studies have consistently demonstrated that pharmacists contribute to reductions in costs in a wide variety of healthcare settings. However, several review articles have highlighted that some of the economic evaluations in the literature were of poor quality. Therefore, future studies with more robust study designs would be of great value to endorse the previous findings, and these should focus on identifying which pharmacist services and interventions are both effective and contribute to the greatest cost savings. High-quality studies of this nature would act as viable decision tools in choosing what clinical pharmacy services should be implemented. Lastly, while the economic effect of clinical pharmacy services is important, it is not the only aspect that must be taken into consideration. The impact that the service has on clinical and humanistic outcomes is also of great significance and must be considered when selecting what pharmacist-provided patient care services could be developed in the future.

\section{Disclosure}

The authors report no conflicts of interest in this work.

\section{References}

1. Hughes DA. From NCE to NICE: the role of pharmacoeconomics. Br J Clin Pharmacol. 2010;70(3):317-319.

2. Lee JK, Alshehri S, Kutbi HI, Martin JR. Optimizing pharmacotherapy in elderly patients: the role of pharmacists. Integr Pharm Res Pract. 2015;4: 101-111.

3. Gallagher J, Byrne S, Woods N, Lynch D, McCarthy S. Cost-outcome description of clinical pharmacist interventions in a university teaching hospital. BMC Health Serv Res. 2014;14:177.

4. Kaboli PJ, Hoth AB, McClimon BJ, Schnipper JL. Clinical pharmacists and inpatient medical care: a systematic review. Arch Intern Med. 2006;166(9):955-964.

5. Schumock GT, Butler MG, Meek PD, Vermeulen LC, Arondekar BV, Bauman JL. Evidence of the economic benefit of clinical pharmacy services: 1996-2000. Pharmacotherapy. 2003;23(1):113-132.
6. Pande S, Hiller JE, Nkansah N, Bero L. The effect of pharmacistprovided non-dispensing services on patient outcomes, health service utilisation and costs in low- and middle-income countries. Cochrane Database Syst Rev. 2013;(2):CD010398.

7. Touchette DR, Doloresco F, Suda KJ, et al. Economic evaluations of clinical pharmacy services: 2006-2010. Pharmacotherapy. 2014;34(8): 771-793.

8. Perez A, Doloresco F, Hoffman JM, et al. Economic evaluations of clinical pharmacy services: 2001-2005. Pharmacotherapy. 2008; 29(1): 128 .

9. De Rijdt T, Willems L, Simoens S. Economic effects of clinical pharmacy interventions: a literature review. Am J Health Syst Pharm. 2008;65(12):1161-1172.

10. Chisholm-Burns MA, Zivin JS, Lee JK, et al. Economic effects of pharmacists on health outcomes in the United States: a systematic review. Am J Health Syst Pharm. 2010;67(19):1624-1634.

11. Barber N, Smith F, Anderson S. Improving quality of health care: the role of pharmacists. Qual Health Care. 1994;3(3):153-158.

12. Hughes DA. An agenda for UK clinical pharmacology: pharmacoeconomics. Br J Clin Pharmacol. 2012;73(6):968-972.

13. Lazarou J, Pomeranz BH, Corey PN. Incidence of adverse drug reactions in hospitalized patients: a meta-analysis of prospective studies. JAMA. 1998;279(15):1200-1205.

14. White TJ, Arakelian A, Rho JP. Counting the costs of drug-related adverse events. Pharmacoeconomics. 1999;15(5):445-458.

15. Pirmohamed M, James S, Meakin S, et al. Adverse drug reactions as cause of admission to hospital: prospective analysis of 18820 patients. BMJ. 2004;329(7456):15-19.

16. Miguel A, Azevedo LF, Araujo M, Pereira AC. Frequency of adverse drug reactions in hospitalized patients: a systematic review and metaanalysis. Pharmacoepidemiol Drug Saf. 2012;21(11):1139-1154.

17. Hughes RG, Ortiz E. Medication errors: why they happen, and how they can be prevented. J Infus Nurs. 2005;28(2 Suppl):14-24.

18. Bates DW, Boyle Dl, van der Vliet MB, Schneider J, Leape L. Relationship between medication errors and adverse drug events. J Gen Intern Med. 1995;10(4):199-205.

19. Beijer HJ, de Blaey CJ. Hospitalisations caused by adverse drug reactions (ADR): a meta-analysis of observational studies. Pharm World Sci. 2002;24(2):46-54.

20. Leendertse AJ, Egberts AC, Stoker LJ, van den Bemt PM. Frequency of and risk factors for preventable medication-related hospital admissions in the Netherlands. Arch Intern Med. 2008;168(17):1890-1896.

21. Sawyer RT, Odom JM, Jennings J, Orr J, Cass AL. Discharge medication reconciliation by pharmacists to improve transitions following hospitalization (DEPTH). 2016. Available from: http://university. ghs.org/wp-content/uploads/2016/05/GHS-Proc-DEPTH-Study.pdf. Accessed December 16, 2016.

22. Yarnall KS, Ostbye T, Krause KM, Pollak KI, Gradison M, Michener JL. Family physicians as team leaders: "time" to share the care. Prev Chronic Dis. 2009;6(2):A59.

23. Yach D, Hawkes C, Gould CL, Hofman KJ. The global burden of chronic diseases: overcoming impediments to prevention and control. JAMA. 2004;291(21):2616-2622.

24. Tinetti ME, Fried TR, Boyd CM. Designing health care for the most common chronic condition: multimorbidity. JAMA.2012;307(23): 2493-2494.

25. Bunting BA, Smith BH, Sutherland SE. The Asheville Project: clinical and economic outcomes of a community-based long-term medication therapy management program for hypertension and dyslipidemia. J Am Pharm Assoc (2003). 2008;48(1):23-31.

26. Khdour MR, Kidney JC, Smyth BM, McElnay JC. Clinical pharmacyled disease and medicine management programme for patients with COPD. Br J Clin Pharmacol. 2009;68(4):588-598.

27. Morello CM, Zadvorny EB, Cording MA, Suemoto RT, Skog J, Harari A. Development and clinical outcomes of pharmacist-managed diabetes care clinics. Am J Health Syst Pharm. 2006;63(14): 1325-1331. 
28. Mossialos E, Courtin E, Naci H, et al. From "retailers" to health care providers: transforming the role of community pharmacists in chronic disease management. Health Policy. 2015;119(5):628-639.

29. Krass I, Mitchell B, Clarke P, et al. Pharmacy diabetes care program: analysis of two screening methods for undiagnosed type 2 diabetes in Australian community pharmacy. Diabetes Res Clin Pract. 2007;75(3):339-347.

30. Goble JA, Rocafort PT. Point-of-care testing: future of chronic disease state management? J Pharm Pract. Epub 2015 Jun 19.

31. Okamoto MP, Nakahiro RK. Pharmacoeconomic evaluation of a pharmacist-managed hypertension clinic. Pharmacotherapy. 2001;21(11): 1337-1344.

32. Chiquette E, Amato MG, Bussey HI. Comparison of an anticoagulation clinic with usual medical care: anticoagulation control, patient outcomes, and health care costs. Arch Intern Med. 1998; 158(15):1641-1647.

33. Hall D, Buchanan J, Helms B, et al. Health care expenditures and therapeutic outcomes of a pharmacist-managed anticoagulation service versus usual medical care. Pharmacotherapy. 2011;31(7):686-694.

34. Osterberg L, Blaschke T. Adherence to medication. $N$ Engl J Med. 2005;353(5):487-497.

35. Simpson SH, Eurich DT, Majumdar SR, et al. A meta-analysis of the association between adherence to drug therapy and mortality. BMJ. 2006;333(7557):15-18

36. DiMatteo MR. Variations in patients' adherence to medical recommendations: a quantitative review of 50 years of research. Med Care. 2004;42(3):200-209.

37. World Health Organization. Adherence to Long-Term Therapies: Evidence for Action. Geneva, Switzerland: WHO; 2003.

38. Maher RL, Hanlon J, Hajjar ER. Clinical consequences of polypharmacy in elderly. Expert Opin Drug Saf. 2014;13(1):57-65.

39. Berg JS, Dischler J, Wagner DJ, Raia JJ, Palmer-Shevlin N. Medication compliance: a healthcare problem. Ann Pharmacother. 1993;27(9 Suppl):S1-S24.

40. Roebuck MC, Liberman JN, Gemmill-Toyama M, Brennan TA. Medication adherence leads to lower health care use and costs despite increased drug spending. Health Aff (Millwood). 2011;30(1): 91-99.

41. Rotta I, Salgado TM, Silva ML, Correr CJ, Fernandez-Llimos F. Effectiveness of clinical pharmacy services: an overview of systematic reviews (2000-2010). Int J Clin Pharm. 2015;37(5):687-697.

42. Lee JK, Grace KA, Taylor AJ. Effect of a pharmacy care program on medication adherence and persistence, blood pressure, and lowdensity lipoprotein cholesterol: a randomized controlled trial. JAMA 2006;296(21):2563-2571.

43. Latif A, Pollock K, Boardman HF. The contribution of the Medicines Use Review (MUR) consultation to counseling practice in community pharmacies. Patient Educ Couns. 2011;83(3):336-344.

44. Trueman P, Taylor DG, Lowson K, et al. Evaluation of the Scale, Causes and Costs of Waste Medicines: Final Report. York: University of York; 2010.

45. Blenkinsopp A, Bond C, Raynor DK. Medication reviews. Br J Clin Pharmacol. 2012;74(4):573-580.

46. US Food and Drug Administration. Drug applications for over-thecounter (OTC) drugs. Available from: http:/www.fda.gov/drugs/ developmentapprovalprocess/howdrugsaredevelopedandapproved/ approvalapplications/over-the-counterdrugs/default.htm. Accessed October 3, 2016.

47. Chui M, Stone J, Martin B, Croes K, Thorpe J. Safeguarding older adults from inappropriate over-the-counter medications: the role of community pharmacists. Gerontologist. 2014;54(6):989-1000.

48. Schmiedl S, Rottenkolber M, Hasford J, et al. Self-medication with over-the-counter and prescribed drugs causing adverse-drug-reactionrelated hospital admissions: results of a prospective, long-term multicentre study. Drug Saf. 2014;37(4):225-235.

49. Watson M, Holland R, Ferguson J, Porteous T, Sach T, Cleland J. Community Pharmacy Management of Minor Illness (the MINA Study). London: Pharmacy Research UK; 2014.
50. Pharmacy Ireland 2020 Working Group. Advancing Clinical Pharmacy Practice to Deliver Better Patient Care and Added Value Services: Interim Report-2008. Dublin, Ireland: Pharmaceutical Society of Ireland; 2008.

51. Hassell K, Noyce P, Rogers A, Harris J, Wilkinson J. A pathway to the GP: the pharmaceutical "consultation" as a first port of call in primary health care. Fam Pract. 1997;14(6):498-502.

52. McCarthy A, O’Nolan G, Long J. Minor Ailments Schemes: An Overview of Experience up to 2015. Dublin, Ireland: Health Research Board; 2016.

53. New Zealand Ministry of Health. Pharmacy Action Plan: 2016 to 2020. Wellington, New Zealand: Ministry of Health; 2016.

54. Irish Pharmacy Union. New pharmacy-based minor ailment scheme for medical card patients. 2016. Available from: https://ipu.ie/home/ article/new-pharmacy-based-minor-ailment-scheme-for-medical-cardpatients-1st-july-2016. Accessed October 3, 2016.

55. [No authors listed]. Minor ailments cost NHS $£ 2$ bn/yr. Pharm J. 2008;280:109.

56. Paudyal V, Hansford D, Cunningham S, Stewart D. Pharmacy assisted patient self care of minor ailments: a chronological review of UK health policy documents and key events 1997-2010. Health Policy. 2011;101(3) 253-259.

57. Marston C, Meltzer H, Majeed A. Impact on contraceptive practice of making emergency hormonal contraception available over the counter in Great Britain: repeated cross sectional surveys. BMJ. 2005;331(7511): 271-273

58. Prosser LA, O’Brien MA, Molinari NA, et al. Non-traditional settings for influenza vaccination of adults: costs and cost effectiveness. Pharmacoeconomics. 2008;26(2):163-178.

59. Steyer TE, Ragucci KR, Pearson WS, Mainous AG. The role of pharmacists in the delivery of influenza vaccinations. Vaccine. 2004; 22(8):1001-1006.

60. Goad JA, Taitel MS, Fensterheim LE, Cannon AE. Vaccinations administered during off-clinic hours at a national community pharmacy: implications for increasing patient access and convenience. Ann Fam Med. 2013;11(5):429-436.

61. Nichol KL. The efficacy, effectiveness and cost-effectiveness of inactivated influenza virus vaccines. Vaccine. 2003;21(16):1769-1775.

62. Doloresco F, Vermeulen LC. Global survey of hospital pharmacy practice. Am J Health Syst Pharm. 2009;66(5 Suppl 3):S13-S19.

63. Auta A, Maz J, Strickland-Hodge B. Perceived facilitators to change in hospital pharmacy practice in England. Int J Clin Pharm. 2015; 37(6):1068-1075.

64. Anderson S. The state of the world's pharmacy: a portrait of the pharmacy profession. J Interprof Care. 2002;16(4):391-404.

65. Bond CA, Raehl CL, Patry R. Evidence-based core clinical pharmacy services in United States hospitals in 2020: services and staffing. Pharmacotherapy. 2004;24(4):427-440.

66. Emmerton L, Marriott J, Bessell T, Nissen L, Dean L. Pharmacists and prescribing rights: review of international developments. J Pharm Pharm Sci. 2005;8(2):217-225.

67. Gourley DR, Fitzgerald WL Jr, Davis RL. Competency, board certification, credentialing, and specialization: who benefits? Am J Manag Care. 1997;3(5):795-801.

68. Anderson SV, Schumock GT. Evaluation and justification of clinical pharmacy services. Expert Rev Pharmacoecon Outcomes Res. 2009;9(6):539-545.

69. Lada P, Delgado G Jr. Documentation of pharmacists' interventions in an emergency department and associated cost avoidance. Am J Health Syst Pharm. 2007;64(1):63-68.

70. Papadopoulos J, Rebuck J, Lober C, et al. The critical care pharmacist: an essential intensive care practitioner. Pharmacotherapy. 2002;22(11):1484-1488

71. Dooley MJ, Allen KM, Doecke CJ, et al. A prospective multicentre study of pharmacist initiated changes to drug therapy and patient management in acute care government funded hospitals. $\mathrm{Br} \mathrm{J} \mathrm{Clin}$ Pharmacol. 2004;57(4):513-521.

72. Alderman CP, Farmer C. A brief analysis of clinical pharmacy interventions undertaken in an Australian teaching hospital. J Qual Clin Pract. 2001;21(4):99-103. 
73. Spinewine A, Fialova D, Byrne S. The role of the pharmacist in optimizing pharmacotherapy in older people. Drugs Aging. 2012;29(6): 495-510.

74. Kopp BJ, Mrsan M, Erstad BL, Duby JJ. Cost implications of and potential adverse events prevented by interventions of a critical care pharmacist. Am J Health Syst Pharm. 2007;64(23):2483-2487.

75. Gallagher J, McCarthy S, Byrne S. Economic evaluations of clinical pharmacist interventions on hospital inpatients: a systematic review of recent literature. Int J Clin Pharm. 2014;36(6):1101-1114.

76. McMullin ST, Hennenfent JA, Ritchie DJ, et al. A prospective, randomized trial to assess the cost impact of pharmacist-initiated interventions. Arch Intern Med. 1999;159(19):2306-2309.

77. Yasunaga D, Tasaka Y, Murakami S, Tanaka A, Tanaka M, Araki H. Economic contributions of pharmaceutical interventions by pharmacists: a retrospective report in Japan. J Pharm Policy Pract. 2016;10:2.

78. Mekonnen AB, McLachlan AJ, Brien JA. Effectiveness of pharmacistled medication reconciliation programmes on clinical outcomes at hospital transitions: a systematic review and meta-analysis. BMJ Open. 2016;6(2):e010003.

79. Hellström LM, Bondesson A, Höglund P, Eriksson T. Errors in medication history at hospital admission: prevalence and predicting factors. BMC Clin Pharmacol. 2012;12:9.

80. Reeder TA, Mutnick A. Pharmacist- versus physician-obtained medication histories. Am J Health Syst Pharm. 2008;65(9):857-860.

81. Karnon J, Campbell F, Czoski-Murray C. Model-based cost-effectiveness analysis of interventions aimed at preventing medication error at hospital admission (medicines reconciliation). J Eval Clin Pract. 2009;15(2):299-306

82. Ensing HT, Stuijt CC, van den Bemt BJ, et al. Identifying the optimal role for pharmacists in care transitions: a systematic review. J Manag Care Spec Pharm. 2015;21(8):614-636.

83. Chinthammit C, Armstrong EP, Warholak TL. A cost-effectiveness evaluation of hospital discharge counseling by pharmacists. J Pharm Pract. 2012;25(2):201-208.

84. Bondesson A, Eriksson T, Kragh A, Holmdahl L, Midlöv P, Höglund P. In-hospital medication reviews reduce unidentified drug-related problems. Eur J Clin Pharmacol. 2013;69(3):647-655.

85. Leape LL, Cullen DJ, Clapp MD, et al. Pharmacist participation on physician rounds and adverse drug events in the intensive care unit. JAMA. 1999;282(3):267-270.

86. Miller G, Franklin BD, Jacklin A. Including pharmacists on consultantled ward rounds: a prospective non-randomised controlled trial. Clin Med. 2011;11(4):312-316.

87. Kucukarslan SN, Peters M, Mlynarek M, Nafziger DA. Pharmacists on rounding teams reduce preventable adverse drug events in hospital general medicine units. Arch Intern Med. 2003;163(17):2014-2018.
88. Fertleman M, Barnett N, Patel T. Improving medication management for patients: the effect of a pharmacist on post-admission ward rounds. Qual Saf Health Care. 2005;14(3):207-211.

89. Jacknin G, Nakamura T, Smally A, Ratzan R. Using pharmacists to optimize patient outcomes and costs in the ED. Am J Emerg Med. 2014; 32(6):673-677.

90. Klopotowska JE, Kuiper R, van Kan HJ, et al. On-ward participation of a hospital pharmacist in a Dutch intensive care unit reduces prescribing errors and related patient harm: an intervention study. Crit Care. 2010;14(5):R174.

91. de Clifford J, Caplygin F, Lam S, Leung B. Impact of an emergency department pharmacist on prescribing errors in an Australian hospital. J Pharm Pract Res. 2007;37(4):284-286.

92. Aldridge VE, Park HK, Bounthavong M, Morreale AP. Implementing a comprehensive, 24-hour emergency department pharmacy program. Am J Health Syst Pharm. 2009;66(21):1943-1947.

93. Wickens HJ, Farrell S, Ashiru-Oredope DA, et al. The increasing role of pharmacists in antimicrobial stewardship in English hospitals. J Antimicrob Chemother. 2013;68(11):2675-2681.

94. Przybylski KG, Rybak MJ, Martin PR, et al. A pharmacist-initiated program of intravenous to oral antibiotic conversion. Pharmacotherapy. 1997; 17(2):271-276.

95. Bond CA, Raehl CL. Clinical and economic outcomes of pharmacistmanaged antimicrobial prophylaxis in surgical patients. Am J Health Syst Pharm. 2007;64(18):1935-1942.

96. Ranchon F, Salles G, Späth HM, et al. Chemotherapeutic errors in hospitalised cancer patients: attributable damage and extra costs. $B M C$ Cancer. 2011;11:478.

97. Han JM, Ah YM, Suh SY, et al. Clinical and economic impact of pharmacists' intervention in a large volume chemotherapy preparation unit. Int J Clin Pharm. 2016;38(5):1124-1132.

98. Dwyer L, Han B, Woodwell D, Rechtsteiner EA. Polypharmacy in nursing home residents in the United States: results of the 2004 National Nursing Home Survey. Am J Geriatr Pharmacother. 2010;8(1): 63-72.

99. Halvorsen KH, Ruths S, Granas AG, Viktil KK. Multidisciplinary intervention to identify and resolve drug-related problems in Norwegian nursing homes. Scand J Prim Health care. 2010;28(2): 82-88.

100. Hawes EM, Misita C, Burkhart JI, et al. Prescribing pharmacists in the ambulatory care setting: experience at the University of North Carolina Medical Center. Am J Health Syst Pharm. 2016;73(18):1425-1433.

101. Erwin PB, Pitlick MK, Peters GL. Maintenance of goal blood pressure, cholesterol, and A1C levels in veterans with type 2 diabetes after discharge from a pharmacist-managed ambulatory care clinic. Diabetes Spectr. 2015;28(4):237-244.
Integrated Pharmacy Research and Practice

\section{Publish your work in this journal}

Integrated Pharmacy Research and Practice is an international, peer-reviewed, open access, online journal, publishing original research, reports, reviews and commentaries on all areas of academic and professional pharmacy practice. This journal aims to represent the academic output of pharmacists and pharmacy practice with particular focus on integrated care. All papers are carefully

\section{Dovepress}

peer reviewed to ensure the highest standards as well as ensuring that we are informing and stimulating pharmaceutical professionals. The manuscript management system is completely online and includes a very quick and fair peer-review system, which is all easy to use. Visit http://www.dovepress.com/ testimonials.php to read real quotes from published authors. 